Article

\title{
Design for Sustainability: The Effect of Lettering Case on Environmental Concern from a Green Advertising Perspective
}

\author{
Yao Song and Yan Luximon * \\ School of Design, The Hong Kong Polytechnic University, Kowloon, Hong Kong; yao.song@connect.polyu.hk \\ * Correspondence: yan.luximon@polyu.edu.hk; Tel.: +852-27665493
}

Received: 30 January 2019; Accepted: 21 February 2019; Published: 4 March 2019

check for updates

\begin{abstract}
Recent green advertising research has focused on the effectiveness of different advertising claims and people's interactions with the environment or environmental concerns, indicating the significant role of visual appeals in influencing people's environmental attitudes. However, surprisingly, only a limited amount of research has addressed the effect of lettering case in green advertising on people's perceptions and their consequent environmental concerns. This study tries to fill in this research gap by showing that uppercase (vs. lowercase) advertising taglines on environmental threats could improve people's fear arousal, advertising congruence, environmental concern and the mediating role of fear arousal and congruence in this process. The managerial implications and limitations are also discussed in this study.
\end{abstract}

Keywords: lettering case; environmental concern; fear arousal; congruence; green advertising

\section{Introduction}

Faced with increasing levels of environmental problems, such as animal extinction, ocean pollution, climate change, and air pollution, people tend to pay more and more attention to concerns relating to environmental issues [1,2]. This increasing environmental concern leads companies or institutes to reconsider the significant role of green advertising in the communication of their pro-environmental claims or environmental sensitivity [3]. In addition, it is common to see variations on the alphabetical combination of lowercase and uppercase letters in green advertising expressing specific, sustainable concepts or meanings to people. For example, different environmental protection institutes or advertising agencies use different lettering cases in their logo designs or adverting campaigns to promote elements related to the environment. While the Go Green Advertising Awards (GGAA), one of the most important green advertising awards, used all lowercase letters in its logo design, "go green", RobecoSAM, an international investment company with a specific focus on sustainability investments, utilised all uppercase letters in its logo, "ROBECOSAM". More commonly, variant usages of uppercase and lowercase were found in advertising taglines. For instance, the World Wide Fund for Nature (WWF), an international non-governmental organisation (NGO) dedicated to wilderness preservation and the reduction of human impact on the environment, used either uppercase letters or lowercase letters in its green advertising. The WWF used the almost all lowercase tagline "Each year, plastic pollution kills more than 100,000 marine creatures" in its marine creature protection adverting, while in its environmental protection advertising, it used the all uppercase tagline 'DON'T LET GARBAGE REPLACE WILDLIFE' [4]. In this case, we might wonder whether the lettering case has an impact on people's perceptions, reactions and consequent environmental concerns.

Recent green advertising research has focused on the effectiveness of different advertising claims and people's interactions with the environment or environmental concerns, indicating the significant 
role of visual appeals in influencing people's environmental attitudes [5,6]. In addition, within various visual advertising appeals, fear appeal plays a crucial role in influencing people's immediate perceptions [7]. In this context, it is common to see environmental threat advertising on issues such as the preservation of animals and the environment in daily green campaigns. For example, Shin et al. [5] have examined the relationships among fear appeals, advertising effectiveness, and environmental involvement, and showed that fear appeal had a positive impact on people's environmental attitudes. Moreover, Xue and Muralidharan [6] further explained the effect of visual environmental appeals on people's environmental attitudes and the moderating role of product involvement.

Lettering case, one of advertising's most important elements, also plays a crucial role in influencing a firm's or institute's performance [8]. However, surprisingly, only a limited amount of research has addressed the effect of lettering case in green advertising on people's perceptions and their consequent environmental concerns. For example, prior research on lettering case has mainly focused on its effect on brand perception [9], brand name [10], and lingual features [11]. Scant research has discussed the role of lettering case in the context of advertising, especially green advertising, regarding people's subjective perceptions and behaviors. In order to fill this research gap, the current study aims to analyze the effects of lettering case in green advertisements on people's perceptions of the advertising and consequent behavioral reactions. The practical implications of the application of lettering case are also discussed in this research.

\section{Literature Review and Hypotheses Development}

\subsection{Green Advertising and Sustainability}

Prior research has long focused on sustainability research or sustainable development from the perspective of various academic disciplines. Different institutes or corporations would like to use green advertising, official websites or project reports implementing their corporate social responsibility (CSR) to expand the program's recipients, related stakeholders, the institute and society in the broader sense $[12,13]$. Moreover, some related indices have also been evaluated by world-leading financial institutes or platforms to measure the sustainability performance of various corporations in the world, such as the S\&P Sustainability Indices, AIChE Sustainability Index and Environmental Sustainability Index $[14,15]$. According to the Brundtland Commission of the United Nations, sustainability refers to a harmonious process in which meeting human development goals, exploiting nature resources, and improving scientific development and inter-country corporation are all pursued in a balanced fashion for this and the next generations [16]. Previous sustainable development or sustainability research has mainly focused on three perspectives: economic, social, and environmental [17]. In particular, organizational sustainability has mainly concerned contributions to environmental protection and sustainability based on corporate responsibility [12]. In this way, sustainable advertising or green advertising worked as an effective tool for corporations or institutes to communicate environmental threats and impact individual and organizational behavior [3]. Since the 1990s, sustainability research has evolved from discussing the specific features or content of green advertising, such as promotion claims [18], trustworthiness [19,20], end price and benefit types [2], and eco-labeling [21], to examining the factors that influence green advertising, such as consumer attitudes [1], willingness to buy [22], and consumer involvement [21]. To specify, green advertising research has mainly concentrated on two areas: its substantive influence and associative influence on people [23]. Whereas the associative influence of green advertising is especially trying to communicate an environmentally friendly image of a given institute or a brand without showing explicit environmental outcomes, substantive influence is concerned with communicating an environmentally friendly image in a more direct manner. Compared with associative influence, substantive influence has tended to elicit a more effective reaction in terms of consumer behavior [24]. In addition, instead of showing the positive outcome of environmental protection in the advertising, inducing fear appeal has also played a significant role in shaping people's behavioral reactions [3]. However, only a limited amount of research has analyzed the specific factors of 
green advertising, such as lettering case, in influencing people's perceptions and consequent behavioral intentions that would help to prevent adverse environmental consequences.

\subsection{Lettering Case, Arousal, and Congruence}

Nowadays, it is common to see that a corporation, based on its general strategy, would like to use a particular advertising tagline to draw people's attention and depict a particular product, service, brand, or even information [25]. The advertising tagline plays a significant role in advertisements in communicating the specific characteristics of a given product, service, or form of information [26]. In this way, the advertising tagline is widely used in various areas, especially in brand differentiation, brand image enhancement, and brand equity communication $[27,28]$. Prior research on advertising taglines has mainly focused on utilizing various methods to improve the consumer experience, such as jingles [29], product-slogan congruence [30], repetition [31,32], brand-slogan linkage [31], parallelism [32], relevance [33], and typeface [34-38]. For example, Henderson et al. [37] attempted to determine the association between different typefaces (elaborate, harmony, natural, flourish weight, and compressed) and people's perceptions of them (pleasing, engaging, reassuring, and prominent).

Lettering case (or case) is the difference between two consecutive terms, uppercase letters (also uppercase, large letters, or, more formally, majuscule) and lowercase letters (also lowercase, small letters, or, more formally, minuscule), in some linguistic writing systems [39]. Two corresponding sets of letters (uppercase and lowercase) are differentiated from each other, in that each one in one set has an equivalent in the other set. Accordingly, the two identical letter cases have the same pronunciation, meaning, alphabetical sequence, and name in alternative written representations [11]. Regarding the specific usage of lettering case, while uppercase letters are frequently used in some specific names, the initial letter of a sentence or the initial letter of an acronym is used in other situations. Ordinary people are actually more familiar with lowercase letter usage than uppercase letter usage in daily life [10,40]. Take the New York Times (NYT, January to March, 1992) corpus, for example, where the frequencies of uppercase and lowercase were not the same. To specify, the total of lowercase letters was around 17.48 times higher than the total of uppercase letters [40].

However, uppercase letters might play a significant role in particular situations, since we might be more accustomed to lowercase letters. According to the conversational norm theory, people tend to figure out the underlying inferences when they encounter unfamiliar situations [41]. In this way, it is easy for uppercase letters to attract people's attention, and the process of drawing attention to visual stimuli is usually related to a concept's 'perceived strength' or 'perceived authority' [9]. For instance, people associate a higher level of perceived strength with potent typefaces, such as larger and heavier typefaces [37]. Regarding lettering case, a similar finding also suggested uppercase letters would be likely to elicit the perception of strength than lowercase letters $[9,37,42]$.

Perceived strength or perceived authority was also related to perceptions of arousal $[43,44]$. From a practical point of view, it is customary to see the application of uppercase letters attracting people's attention, especially in communicating specific information by emphasizing, reminding, and cautioning [42]. Accordingly, people tend to have a higher level of arousal perception and perceived authority, and their consequent behavior is also influenced, when faced with authoritative advertising [45]. For instance, it is common to see a full and large uppercase warning sign in a public space, such as 'STOP' or 'NON-SMOKING', which tends to attract attention and show their authoritative role. When faced with such strong, authoritative advertising, people experience a higher level of fear arousal, paying more attention to the advertising's influential and dominant information [46,47]. Regarding the reaction people have to the tagline for the given information, the spillover effect suggests that the cognitive reaction to the tagline would transfer into the given product, service, or brand [48,49]. Therefore, we could expect that the fear arousal invoked by uppercase letters in a tagline could spill over into environmental threat advertising.

Moreover, previous research on social psychology has suggested that fear and threats are closely related to perceived authority or perceived strength [50-52]. For example, Feldman and Stenner [52] 
argued that various forms of threat would contribute to authoritarianism, since people tended to perceive insecurity and want to 'escape from freedom' when faced with an uncertain situation. In other words, a threat environment would be more congruous with perceived authority. In terms of 'congruence', it was commonly used in the fields related to advertising, brand extension, cultural perspective, and personality integration [53-55]. Prior research has emphasized the effect of different elements of congruence in advertising. For instance, Lee and Mason [56] adapted the concept of congruence from social cognition first, and then discussed the effect of two dimensions of congruence, relevancy and expectancy, in the context of advertising. To specify, in complex advertising information processing, congruence referred to 'the general focus of a story to which the plot adheres', and it played a significant role in processing the impression-based prior expectancy of a given advertisement. While relevancy refers to the extent to which a factor or a component helps to identify the related information presented by the advertising, expectancy was more associated with the extent to which an item or some information (verbal or visual) was connected to a predetermined pattern from the advertising. In addition, Moore et al. [57] further discussed the effect of congruence between color and context on people's attitudes and attention attraction from both a verbal and visual perspective. While incongruence in advertising or text-color contrast might attract people's attention, congruence in advertising improves people's information acceptability.

\subsection{Congruence, Arousal, and Environmental Concern}

Previous research has long focused on the effects of different factors on pro-social behavior and environmental perceptions, such as environmental attitudes or environmental concerns [58-63]. For example, moral salience improves people's environmental attitudes and increases the probability of prosocial behaviors [60,62]. According to the extended parallel processing model (EPPM) and protection motivation theory (PMT), people like to follow recommendations for behavioral regulation after being exposed to related information on perceived coping efficacy, improving their intention for actual behavioral change [64-66]. Regarding people's low level of self-efficacy in protecting the natural environment, it is important to expose efficacy-related information to the public, thereby improving people's awareness and coping efficacy. An adaptive response would be triggered and performed through the exposure of self-efficacy or coping efficacy [64]. In addition, the EPPM suggests that the cognition of fear arousal created by a fear appeal would be triggered by efficacy cognitions, influencing people's consequent behavior changes regarding inconsistent perceptions, attitudes, and intentions. As a result, people also tend to follow recommendations for behavioral regulation when they strongly perceive the threat derived from fear appeals [65,67].

Previous research has discussed the different roles of fear arousal in people's perception and evaluation processes. The majority of fear arousal studies believe it plays a significant role in improving coping behavior in the fear-driven model $[3,7,68-70]$. For example, emotion is considered to offer an important perspective for understanding threat evaluation and consequent behavior, since it can influence people's goal setting [7]. The threat evaluation process determines whether a stimulus is favorable or not for people's goal setting by introducing a change in emotions, such as fear arousal. In this way, fear arousal could induce protection behavior, such as avoiding potential danger and prompting related coping behavior $[3,66,69,70]$. Moreover, fear arousal could also improve the severity evaluation of a threat appeal, especially in green advertising [3,70]. For instance, Hartmann et al. [3] argued that a theoretical pro-environmental coping model where fear arousal functioned as a mediator of threat evaluation, such as in environmental advertising and threat appeals, would have an impact on pro-environmental behavior. Furthermore, the mediating role of fear arousal in threat appeals on behavioral intentions has also been discussed from different perspectives, such as anti-speeding road-safety TV ads [71], public health campaigns [7], anti-smoking campaigns [72], information security behavior [73], positive engagement with the climate [74], and healthy food promotion for the younger generation [75]. Therefore, fear arousal prompted by environmental threat advertising seems to increase people's environmental coping behaviors, such as environmental concerns. Skurka et al. [76] 
suggested that video fear appeals, which have been considered as a default emotional setting, could be effective in motivating people's climate-change-related intentions and risk perceptions. In addition, Tannenbaum et al. [64] also showed that people had higher intentions to engage in climate change activism after their fear was aroused about climate change. However, some studies have argued that the process through which arousal interacted with behavioral reactions is nuanced, contingent on cognitive appraisals and responses [77]. According to the Yerkes-Dodson-based model [78], the relationship between people's behavioral reactions and mental arousal interacts as an inverted U-shaped relationship: People's behavioral reactions are improved with an increasing level of psychological arousal; but, up to a point where the levels of arousal are too high, people's behavioral reactions decrease to some extent. Therefore, the mediating role of fear arousal on environmental concern should be considered in green advertising.

Similarly, prior research has suggested that advertising congruence could improve the effectiveness of an advertisement. For example, Misra and Beatty [79] used the context of celebrity spokesperson and brand congruence to figure out how celebrity-brand congruence works as an efficient way to improve the effectiveness of advertising. In particular, they found that the recall of a brand, the transfer of an effect from the spokesperson to a brand, and the transfer of an effect to a brand were significantly improved when the celebrity and brand were matched. Given that uppercase letters would relate more to an environmental threat advertising scenario, it is reasonable to predict that the effectiveness of green advertising in eliciting environmental concern would be improved when the tagline in the advertisement was written in uppercase. Therefore, the mediating role of congruence on environmental concern should also be studied in detail. To sum up, lettering case could potentially improve fear arousal and advertising congruence, having a mediating impact on people's environmental concern.

\subsection{Summerised Literature and Hypotheses}

In order to clearly illustrate the relationships between lettering case, congruence, arousal, and environmental concern, we summarized the most relevant literature in Table 1 . We propose the following hypotheses (Figure 1):

H1a. An uppercase (vs. lowercase) advertising tagline causes people to perceive a higher level (vs. a lower level) of fear arousal in environmental threat advertising.

H1b. Fear arousal would mediate the effect of lettering case in environmental threat advertising on environmental concern.

H2a. An uppercase (vs. lowercase) advertising tagline causes people to perceive a higher level (vs. a lower level) of congruence in environmental threat advertising.

H2b. Congruence would mediate the effect of lettering case in environmental threat advertising on environmental concern.

H3. An uppercase (vs. lowercase) advertising tagline causes people to have a higher level (vs. a lower level) of environmental concern in environmental threat advertising.

Table 1. Summary of relevant concepts in the previous literature.

\begin{tabular}{llccc}
\hline \multicolumn{1}{c}{ Relationship } & \multicolumn{1}{c}{ Measures } & Technique & Direction & Studies \\
\hline Lettering Case & Uppercase/lowercase-Authority/familiarity & Experiment & + & {$[9]$} \\
$->$ & Familiarity-Authority & Experiment & - & {$[42]$} \\
Arousal & Authority-Arousal & Experiment & + & {$[9,44,45]$} \\
\hline Lettering Case & Appropriate typeface-Congruence & Experiment \& survey & + & {$[34-38]$} \\
$->$ & Appropriate slogan-Congruence & Experiment & + & {$[30]$} \\
Congruence & Appropriate culture-Congruence & Survey & + & {$[54]$} \\
\hline \multirow{3}{*}{ Arousal \& Congruence } & Congruence in ad context-Ad attitude & Experiment & + & {$[57]$} \\
$\rightarrow>$ & Congruence in ad elements-Ad effectiveness & Experiment & + & {$[77]$} \\
Environmental Concern & Fear appeal-Environmental behavior & Experiment \& interview & + & {$[64,74]$} \\
& Fear appeal-Healthy behavior & Experiment & + & {$[7,72,75]$} \\
& Threat appeal-Severity evaluation & Experiment \& survey & + & {$[70,73,76]$} \\
\hline
\end{tabular}




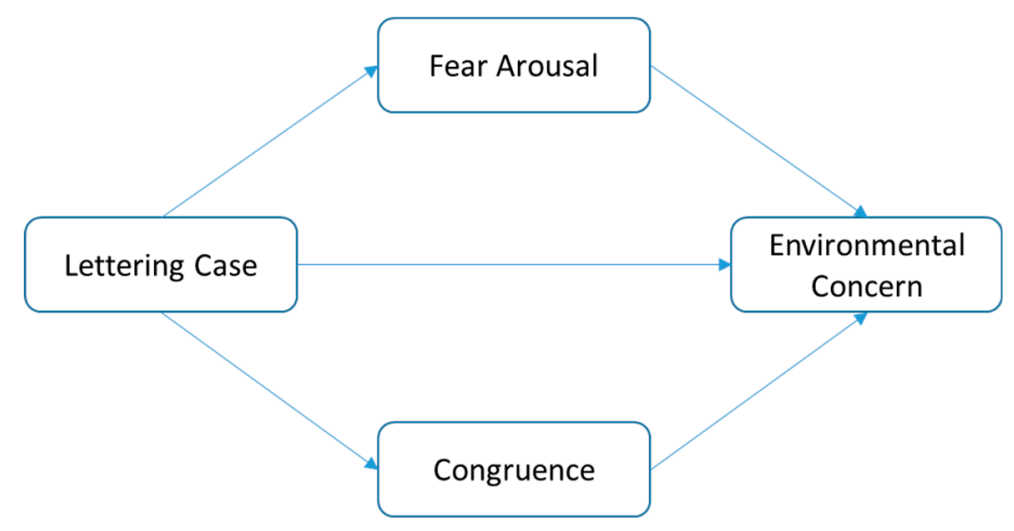

Figure 1. Conceptual framework of the current study.

\section{Research Method}

The aim of this study was to investigate the belief that an uppercase (vs. a lowercase) green advertising tagline could improve people's environmental concerns and the mediating role of fear arousal and congruence in this process. The causality relationship of the theoretical model was examined though a behavioral experimental approach.

\subsection{Experiment Design and Stimuli}

The experiment employed a between-subjects design that contained three lettering scenarios: all lowercase, initial letter uppercase, and all uppercase. One professional advertising designer made these three environmental threat advertisements, which were adapted from a NGO website [80] in the experiment (for stimuli, see Figure 2).

To avoid potential confounding influences stemming from existing perceptions of green advertising or other fields, we carefully controlled the potential confounders. To specify, for the lettering case with either lowercase letters or uppercase letters, the total length of the slogan was controlled in the same manner. The font used was Franklin Gothic, since this typeface is widely used in advertising [81]. The tagline was "save the planet", which is commonly used in green campaigns. In addition, other advertising elements, such as positioning, were also controlled to avoid any cofounding effects.

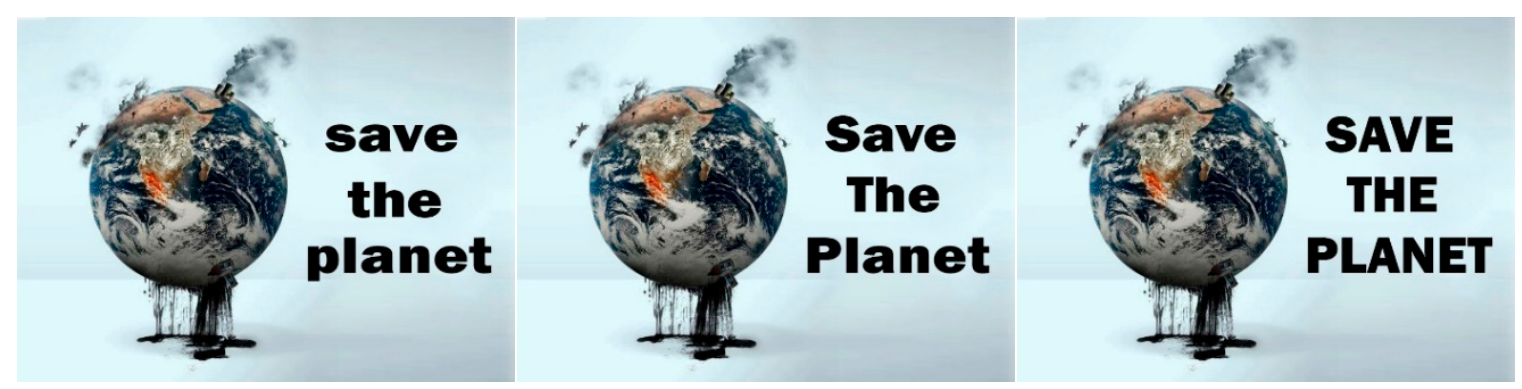

Figure 2. Experiment stimuli used in this study.

\subsection{Subject and Procedure}

In order to analyze the relationship between lettering case and its effect, a sample group (from Amazon Mechanical Turk, AMT) was recruited and participated in the experiment. AMT is a reliable data collection platform to address the lettering case issue, since we could specifically choose U.S. and Canadian AMT workers whose official language was English. The participants were required to have basic English reading ability. In addition, a large number of social experiments have been used to collect data through AMT, and showed adequate quality and reliability compared with physical lab experiments [82]. 
To avoid self-selection and professional survey takers, Qualtrics was utilized, since it applies by-invitation-only online panel recruitment, thus attracting a cross-section that better generalizes to the population to a significant extent. The experiment was designed to examine the main effect of lettering case on environmental concern, and the mediating role of fear arousal and congruence in shaping people's perceptions.

A total of 244 participants were recruited for this study (mean age $=43.32$ years; 145 men and 99 women). They first consented to take part in the study, and then they were randomly assigned to one of three scenarios. To specify, 81,83 , and 80 participants were assigned to the all lowercase, all uppercase, and initial letter uppercase scenarios, respectively. They were required to look at the green advertising for five seconds, and then they were required to answer several questions on the given advertising.

This experiment measured the influence of different lettering case taglines on people's fear arousal, advertising congruence, and environmental concern. Perceived fear arousal in green advertising was measured with three items ("This advertising makes me feel frenzied" / "This advertising makes me feel awake" / "This advertising makes me feel aroused) on a seven-point Likert rating scale [47]. In addition, congruence was measured with three items ("This ad slogan is compatible with the ad" /"This ad slogan is a good fit for the ad" / "This ad slogan matches the ad well") on a seven-point Likert rating scale $[79,83]$. Lastly, environmental concern was measured with three items ("Mankind is severely abusing the environment" / There are limits to growth beyond which our industrialized society cannot expand" / "Humans must live in harmony with nature in order to survive") on a nine-point Likert rating scale $[84,85]$.

\section{Data Analysis and Results}

Tests for H1a and H2a, one-way ANOVA and post-hoc Tukey HSD were performed with lettering case (all lowercase vs. initial-letter uppercase vs. all uppercase) as the independent variable, and fear arousal, congruence, and environmental concern as the dependent variables. According to the results of the ANOVA, we found a significant difference in fear arousal and congruence among these three scenarios (fear arousal: $F(2,241)=6.228, p<0.05$; congruence: $F(2,241)=9.220, p<0.05$; see Tables $2 \& 3$ and Figures $3 \& 4)$.

Regarding H1a, the post-hoc Tukey HSD results revealed that people in the all uppercase letter advertising scenario showed significantly higher fear arousal than those in the all lowercase letter advertising scenario (Mean $=4.68$ vs. $3.94, \mathrm{SD}=1.47$ vs. 1.61 ; Tukey HSD, $\mathrm{p}<0.05$ ). While people grouped in the initial letter uppercase advertising scenario also showed significantly higher fear arousal than those in the all lowercase letter scenario (Mean $=4.63$ vs. $3.94, \mathrm{SD}=1.39$ vs. 1.61 ; Tukey HSD, $\mathrm{p}<0.05$ ), there was no significant difference between the initial letter uppercase and all uppercase advertising scenario in terms of fear arousal (Tukey HSD, $p=0.97$ ).

Regarding H2a, the post-hoc Tukey HSD results showed that people in the all uppercase letter advertising scenario showed significantly higher congruence than those in the all lowercase letter advertising scenario (Mean $=5.72$ vs. $4.82, \mathrm{SD}=1.06$ vs. 1.64 ; Tukey HSD, $\mathrm{p}<0.05$ ). While people in the initial letter uppercase advertising scenario also showed significantly higher congruence than those in the all lowercase letter scenario (Mean $=5.39$ vs. $4.82, \mathrm{SD}=1.29$ vs. 1.64 ; Tukey HSD, $\mathrm{p}<0.05$ ), there was no significant difference between the initial letter uppercase and the all uppercase advertising scenario in terms of congruence (Tukey HSD, $\mathrm{p}=0.26$ ).

Table 2. ANOVA results for fear arousal.

\begin{tabular}{cccccc}
\hline & Sum of Squares & df & Mean Square & F & Sig. \\
\hline Between Groups & 28.023 & 2 & 14.011 & 6.228 & 0.002 \\
Within Groups & 542.166 & 241 & 2.250 & & \\
Total & 570.189 & 243 & & & \\
\hline
\end{tabular}


Table 3. ANOVA results for congruence.

\begin{tabular}{cccccc}
\hline & Sum of Squares & df & Mean Square & F & Sig. \\
\hline Between Groups & 33.877 & 2 & 16.938 & 9.220 & 0.000 \\
Within Groups & 442.745 & 241 & 1.837 & & \\
Total & 476.621 & 243 & & & \\
\hline
\end{tabular}

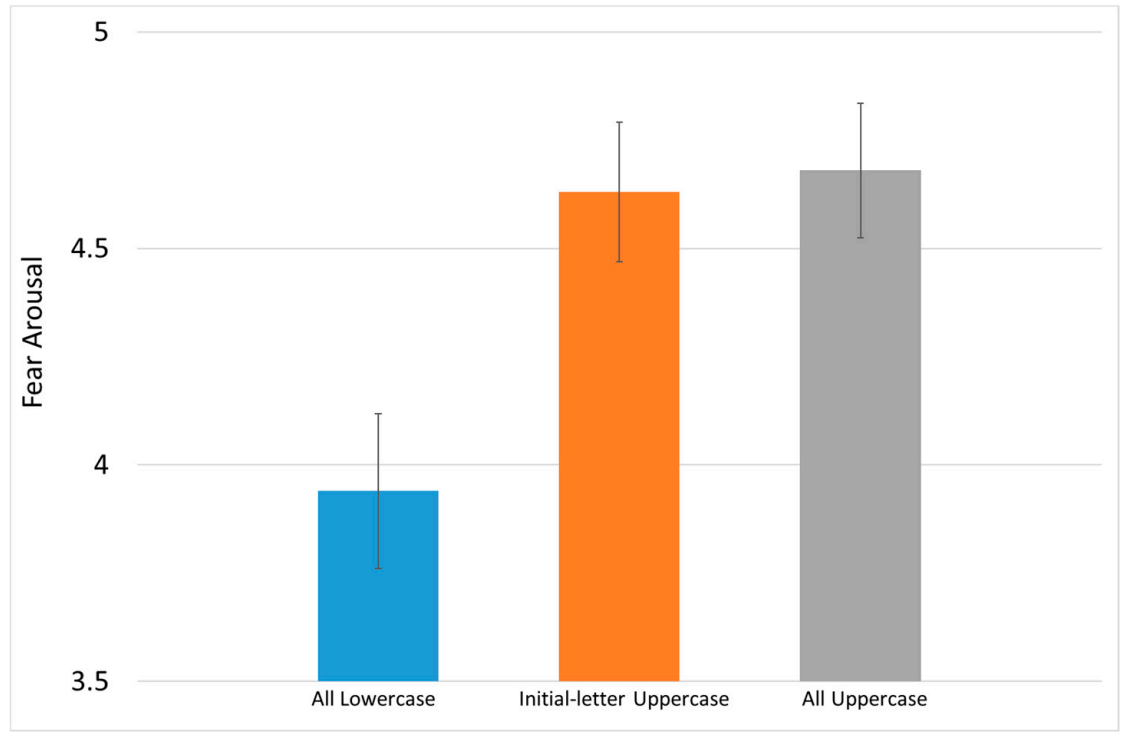

Figure 3. The results for different effects of lettering case on fear arousal.

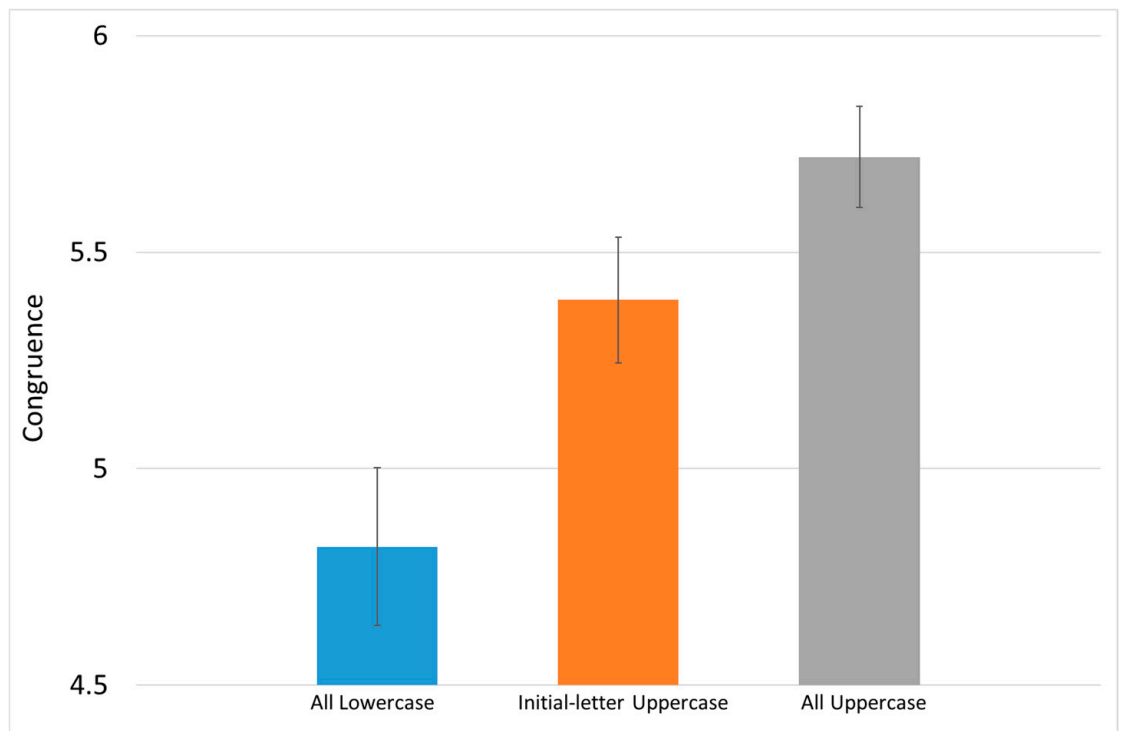

Figure 4. The results for different effects of lettering case on congruence.

Regarding $\mathrm{H} 3$, the results of the ANOVA similarly showed a significant difference in environmental concern among these three scenarios (one-way ANOVA, $\mathrm{F}(2,241)=4.864$, $\mathrm{p}<0.05$; see Table 4 and Figure 5). The post-hoc Tukey HSD results showed that people in the all uppercase letter advertising scenario showed no significantly higher environmental concern than those in the all lowercase letter advertising scenario (Mean $=7.18$ vs. $6.76, \mathrm{SD}=1.48$ vs. 1.64 ; Tukey HSD, $p=0.19$ ). While people in the initial letter uppercase advertising scenario showed significantly higher environmental concern than those in the all lowercase letter scenario (Mean $=7.52$ vs. $6.76, \mathrm{SD}=1.11$ vs. 1.64; Tukey HSD, $\mathrm{p}<0.05)$, there was no significant difference between the initial letter uppercase and the all uppercase advertising scenario in terms of environmental concern (Tukey HSD, $p=0.34$ ). 
Table 4. ANOVA results for environmental concern.

\begin{tabular}{cccccc}
\hline & Sum of Squares & df & Mean Square & F & Sig. \\
\hline Between Groups & 23.320 & 2 & 11.660 & 4.864 & 0.008 \\
Within Groups & 577.673 & 241 & 2.397 & & \\
Total & 600.993 & 243 & & & \\
\hline
\end{tabular}

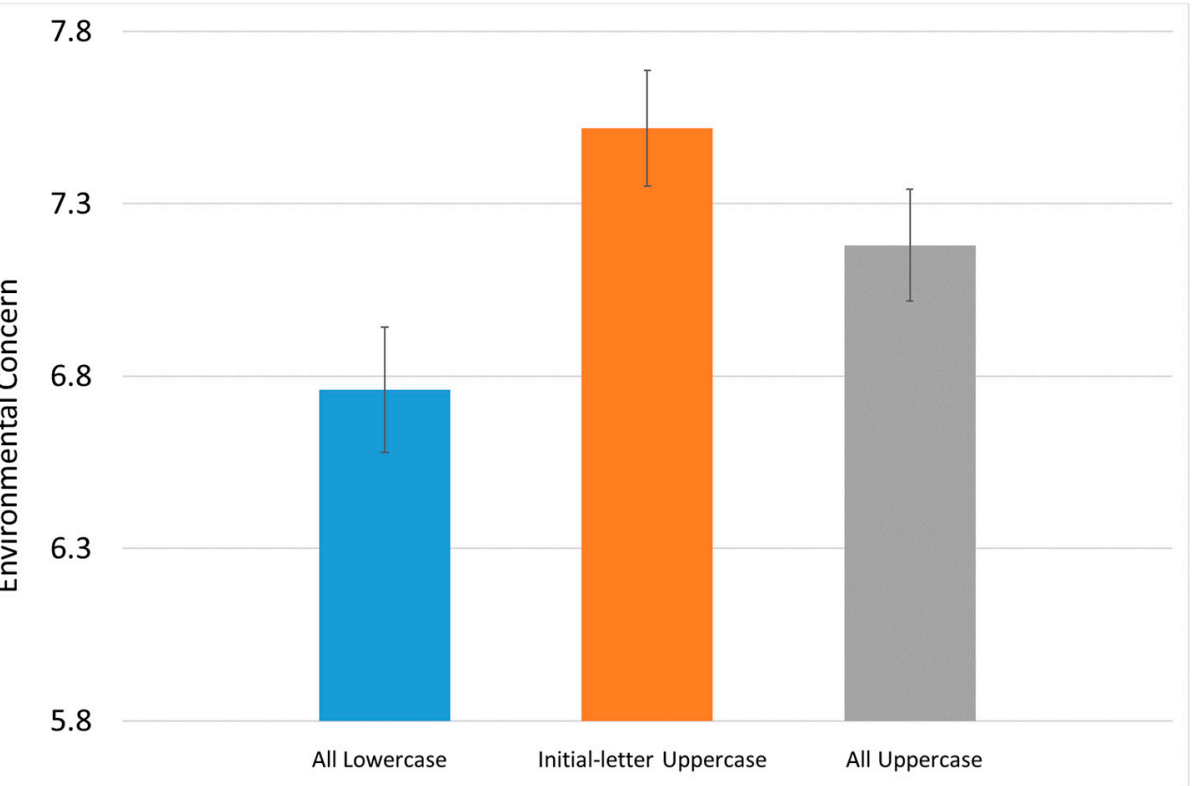

Figure 5. The results for different effects of lettering case on environmental concern.

In order to test $\mathrm{H} 2 \mathrm{a}$ and $\mathrm{H} 2 \mathrm{~b}$ regarding the mediating role of fear arousal and congruence, environmental concerns were regressed on the lettering case (uppercase vs. initial letter uppercase vs. lowercase) through the PROCESS SPSS macro [86] (Model 4, $\mathrm{n}=5000$ resamples).

For $\mathrm{H} 2 \mathrm{a}$, the results indicated that lettering case was a significant independent variable of fear arousal, $\beta=0.3463, \mathrm{SE}=0.1189, \mathrm{p}<0.05$, and that it was also a significant independent variable of environmental concern, $\beta=0.2881, \mathrm{SE}=0.1199, \mathrm{p}<0.05$. Fear arousal was also a significant independent variable of environmental concern, $\beta=0.2650, \mathrm{SE}=0.0637, \mathrm{p}<0.05$. In addition, the results showed the indirect effect, $\mathrm{LLCI}=0.0258$ and $\mathrm{ULCI}=0.1756$, does not contain 0 , implying that the mediating role of fear arousal was significant (see Figure 6).

For $\mathrm{H} 2 \mathrm{~b}$, the results indicated that lettering case was a significant independent variable of congruence, $\beta=0.2856, \mathrm{SE}=0.1091, \mathrm{p}<0.05$, and it was also a significant independent variable of environmental concern, $\beta=0.2647$, $\mathrm{SE}=0.1154, \mathrm{p}<0.05$. In addition, congruence was a significant independent variable of environmental concern, $\beta=0.4031$, SE $=0.0671, \mathrm{p}<0.05$. Furthermore, the results showed the indirect coefficient was significant, $\beta=0.1151, \mathrm{SE}=0.0550, \mathrm{LLCI}=0.0212$, $\mathrm{ULCI}=0.2357$ (see Figure 7).

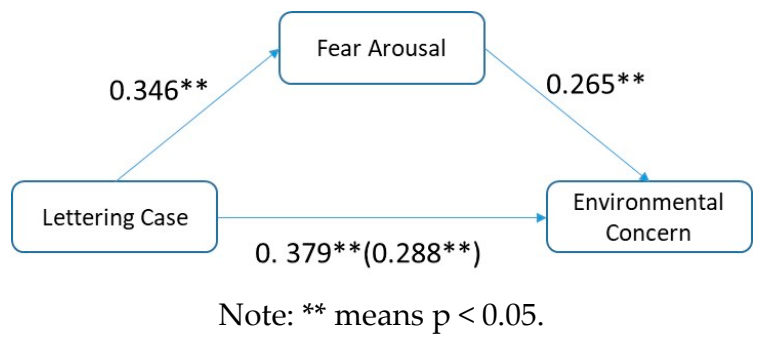

Figure 6. The mediation effect of fear arousal. 


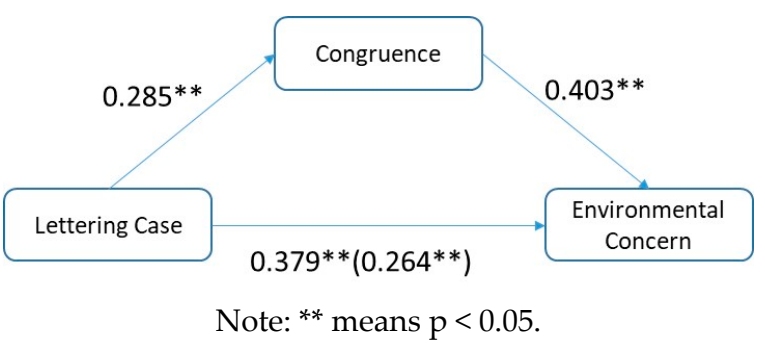

Figure 7. The mediation effect of congruence.

\section{Conclusions and Discussion}

This study aimed to explore whether different lettering cases would have an impact on people's perceptions and consequent behavioral changes. The current study empirically tested the theoretical framework of lettering case, fear arousal, congruence, and environmental concern. For uppercase letter advertising (vs. lowercase letter), we found that people tended to have a higher level of fear arousal and congruence (supporting $\mathrm{H} 1 \mathrm{a}$ and $\mathrm{H} 2 \mathrm{a}$ ) and exhibited a higher level of environmental concern when it was used in green advertising (supporting H3). To specify, an all uppercase letter tagline and an initial letter uppercase tagline tended to evoke a stronger perception of fear arousal and congruence in environmental threat advertising compared to an all lowercase letter tagline, while there was no statistical difference between the all uppercase tagline and the initial letter uppercase tagline. Similarly, an initial letter uppercase tagline also significantly improved people's environmental concern compared with an all lowercase tagline, while there was no significant difference between the all uppercase tagline and the initial letter uppercase tagline, and between all uppercase and all lowercase scenarios. This process was mediated by congruence and fear arousal (supporting H2a and $\mathrm{H} 2 \mathrm{~b}$ ). Previous study suggested that the relationship between people's behavioral reactions and mental arousal interacts as an inverted U-shaped relationship [77]. Although the results from the current study did not find the statistically significant U-shaped relationship, environmental concern of the initial letter uppercase scenario was the highest in all three scenarios. The experimental context in Ben-Zeev et al. [77] was an actual behavioral experiment which contained the combinations of five senses. In the future study, we could implement multiple senses scenarios with even higher level of fear arousal to further validate the mediating role of fear arousal on environmental concern.

This study provides the following theoretical contributions. Firstly, previous research on green advertising has emphasized the effects of environmental claims, perceived trustworthiness, end prices end, and label issues on environmental attitudes and environmental concerns $[2,18,20,24]$. This study endeavored to supplement and extend the literature on environmental concerns from a visual advertising perspective, highlighting the role of lettering case in people's fear perceptions, congruence, and consequent behavioral reactions concerning environmental threat advertising [87]. In addition, the results of this study are consistent with recent neuroscientific research findings on the role of the amygdala in visual fear information processing [88-90]. To specify, fear stimuli simultaneously activate fear and attract attention, and this effect is highly correlated with a subcortical brain network centered in the amygdala. Secondly, only a limited number of studies have analyzed the effects of lettering case on the perceptions of brands and companies, such as perceived friendliness, perceived authority, and perceived strength [9], and there have been few studies discussing the spillover effect of lettering case on advertising perceptions and the consequent behavioral reactions, which have been under-researched in prior empirical studies. Faced with increasing environmental problems, drawing people's attention to environmental issues and improving their environmental concerns plays an important role in green advertising [1]. Regarding this context, it is necessary to analyze the underlying mechanism of the effects of lettering case on people's environmental concerns. This study develops a more complete framework on how lettering case affects people's environmental concerns by identifying the mediating role of congruence and fear arousal in environmental threat advertising. Lastly, previous research on advertising taglines has mainly focused on the semantic and 
linguistic perspective [91,92]. For example, Puntoni [91] suggested the effect of tagline languages in an increasingly globalized marketplace. However, this research largely neglected to analyze the effect of taglines from a lettering case perspective that would also contribute to the literature on advertising tagline research.

\section{Implications, Limitations, and Future Research}

This study offers the following managerial implications. Firstly, it might help NGOs or environment protection institutes to communicate environmental threats in their advertising. Raising public fears of negative environmental consequences is very helpful in improving environment protection activities [3]. However, only a limited amount of research has addressed how to strengthen environmental threat advertising through the application of the appropriate lettering case. This study will help to illuminate a new path for NGOs or other related institutes to communicate specific information to the public more effectively and influence their consequent environmental concerns through design.

There are a few limitations of this study that are worth noticing to highlight directions for future investigation. This study mainly focused on lettering case out of many other advertising features that also play important roles in fear appeal advertising, such as the role of culture, message involvement, message acceptance, and rhetoric factors [93-95]. It would be interesting to explore the association between those attributes and lettering case, and their interactions in terms of environmental concern. In addition, this study emphasized green advertising designed from an environmental threat perspective. However, there are also many green advertisements oriented towards the positive attributes of a green product. It would also be interesting to explore whether the type of green message and lettering case would have a moderating impact on environmental concerns. Moreover, in terms of environmental perceptions, previous studies have discussed that there are different types of perceptions, such as environmental attitudes, environmental concerns, and moral salience, which could all increase people's pro-social behaviors [58-63]. However, the relationship among those concepts and the effect of lettering case on those concepts remains ambiguous, requiring further clarification in the future. Lastly, the current research mainly focused on exploring the effect from an NGO perspective, while assessing the way to influence public consumption or consumer behavior would also help facilitate environment protection. In fact, many companies have run green advertising to show their sensitivity regarding environmental protection. Future research could try to further explore the impact of commercial advertising on product attitudes and related environmental concerns.

Author Contributions: Conceptualization, Y.S.; Methodology, Y.S. and Y.L.; Data curation, Y.S. and Y.L.; Writing, Y.S. and Y.L.; Supervision, Y.L.

Funding: This research was funded by the UGC Funding Scheme and RISUD from The Hong Kong Polytechnic University.

Conflicts of Interest: The authors declare no conflict of interest.

\section{References}

1. Haytko, D.; Matulich, E. Green advertising and environmentally responsible consumer behaviors: Linkages examined. J. Manag. Mark. Res. 2008, 1, 2.

2. Royne, M.B.; Martinez, J.; Oakley, J.; Fox, A.K. The Effectiveness of Benefit Type and Price Endings in Green Advertising. J. Advert. 2012, 41, 85-102. [CrossRef]

3. Hartmann, P.; Apaolaza, V.; D'Souza, C.; Barrutia, J.M.; Echebarria, C. Environmental threat appeals in green advertising. Int. J. Advert. 2014, 33, 741-765. [CrossRef]

4. WWF. Endangered Species Conservation / World Wildlife Fund. Available online: https://Www. worldwildlife.org/ (accessed on 16 December 2018).

5. Shin, S.; Ki, E.-J.; Griffin, W.G. The effectiveness of fear appeals in "green" advertising: An analysis of creative, consumer, and source variables. J. Mark. Commun. 2017, 23, 473-492. [CrossRef] 
6. Xue, F.; Muralidharan, S. A Green Picture is Worth A Thousand Words?: Effects of Visual and Textual Environmental Appeals in Advertising and the Moderating Role of Product Involvement. J. Promot. Manag. 2015, 21, 82-106. [CrossRef]

7. Witte, K.; Allen, M. A Meta-Analysis of Fear Appeals: Implications for Effective Public Health Campaigns. Heal. Educ. Behav. 2000, 27, 591-615. [CrossRef] [PubMed]

8. Mathur, L.K.; Mathur, I. The Effect of Advertising Slogan Changes on the Market Values of Firms. J. Advert. Res. 1995, 35, 59.

9. Xu, X.; Chen, R.; Liu, M.W. The effects of uppercase and lowercase wordmarks on brand perceptions. Mark. Lett. 2017, 28, 449-460. [CrossRef]

10. Perea, M.; Jiménez, M.; Talero, F.; López-Cañada, S. Letter-case information and the identification of brand names. Br. J. Psychol. 2015, 106, 162-173. [CrossRef] [PubMed]

11. Nesbitt, A. The History and Technique of Lettering, 1st ed.; Dover Publications: New York, NY, USA, 1957; ISBN 0486204278.

12. Nyilasy, G.; Gangadharbatla, H.; Paladino, A. Perceived Greenwashing: The Interactive Effects of Green Advertising and Corporate Environmental Performance on Consumer Reactions. J. Bus. Ethics 2014, 125, 693-707. [CrossRef]

13. Leonidou, L.C.; Leonidou, C.N.; Palihawadana, D.; Hultman, M. Evaluating the green advertising practices of international firms: A trend analysis. Int. Mark. Rev. 2011, 28, 6-33. [CrossRef]

14. Sustainability Indices Homepage. Available online: https://www.sustainability-indices.com/ (accessed on 14 December 2018).

15. Sustainability Index / AIChE. Available online: https://www.aiche.org/ifs/resources/sustainability-index (accessed on 14 December 2018).

16. Butlin, J. Our common future. By World commission on environment and development. J. Int. Dev. 2011, 1, 284-287. [CrossRef]

17. Epstein, M.J. Making Sustainability Work; Routledge: London, UK, 2018; ISBN 9781351280129.

18. Rex, E.; Baumann, H. Beyond ecolabels: What green marketing can learn from conventional marketing. J. Clean. Prod. 2007, 15, 567-576. [CrossRef]

19. Matthes, J.; Wonneberger, A. The Skeptical Green Consumer Revisited: Testing the Relationship Between Green Consumerism and Skepticism Toward Advertising. J. Advert. 2014, 43, 115-127. [CrossRef]

20. Do Paço, A.M.F.; Reis, R. Factors Affecting Skepticism toward Green Advertising. J. Advert. 2012, 41, 147-155. [CrossRef]

21. Atkinson, L.; Rosenthal, S. Signaling the Green Sell: The Influence of Eco-Label Source, Argument Specificity, and Product Involvement on Consumer Trust. J. Advert. 2014, 43, 33-45. [CrossRef]

22. Hartmann, P.; Apaolaza-Ibáñez, V. Consumer attitude and purchase intention toward green energy brands: The roles of psychological benefits and environmental concern. J. Bus. Res. 2012, 65, 1254-1263. [CrossRef]

23. Gabzdylova, B.; Raffensperger, J.F.; Castka, P. Sustainability in the New Zealand wine industry: Drivers, stakeholders and practices. J. Clean. Prod. 2009, 17, 992-998. [CrossRef]

24. Carlson, L.; Grove, S.J.; Kangun, N.; Polonsky, M.J. An International Comparison of Environmental Advertising: Substantive versus Associative Claims. J. Macromark. 1996, 16, 57-68. [CrossRef]

25. Dowling, G.R.; Kabanoff, B. Computer-aided content analysis: What do 240 advertising slogans have in common? Mark. Lett. 1996, 7, 63-75. [CrossRef]

26. Dimofte, C.V.; Yalch, R.F. Consumer Response to Polysemous Brand Slogans. J. Consum. Res. 2007, 33, 515-522. [CrossRef]

27. Dahlén, M.; Rosengren, S. Brands affect slogans affect brands? Competitive interference, brand equity and the brand-slogan link. J. Brand Manag. 2005, 12, 151-164. [CrossRef]

28. Rosengren, S.; Dahlén, M. Brand-Slogan Matching in a Cluttered Environment. J. Mark. Commun. 2006, 12, 263-279. [CrossRef]

29. Yalch, R.F. Memory in a jingle jungle: Music as a mnemonic device in communicating advertising slogans. J. Appl. Psychol. 1991, 76, 268-275. [CrossRef]

30. Van Rompay, T. Symbolic Meaning Integration in Design and Its Influence on Product and Brand Evaluation; MinD-Designing for People with Dementia View Project PhD Project on the Experience of Hospitality-Communication Studies; University of Twente: Enschede, The Netherland, 2009; Volume 3. 
31. Kohli, C.; Leuthesser, L.; Suri, R. Got slogan? Guidelines for creating effective slogans. Bus. Horiz. 2007, 50, 415-422. [CrossRef]

32. Olivera, P.; Sacristán, M.; Baño, A.; Fernández, E. Persuasion and advertising English: Metadiscourse in slogans and headlines. J. Pragmat. 2001, 33, 1291-1307. [CrossRef]

33. Van Mulken, M.; van Enschot-van Dijk, R. Puns, relevance and appreciation in advertisements. J. Pragmat. 2005, 37, 707-721. [CrossRef]

34. Van Rompay, T.J.L.; Pruyn, A.T.H. When visual product features speak the same language: Effects of shape-typeface congruence on brand perception and price expectations. J. Prod. Innov. Manag. 2011, 28, 599-610. [CrossRef]

35. Childers, T.L.; Jass, J. All Dressed Up With Something to Say: Effects of Typeface Semantic Associations on Brand Perceptions and Consumer Memory. J. Consum. Psychol. 2002, 12, 93-106. [CrossRef]

36. Doyle, J.R.; Bottomley, P.A. Font appropriateness and brand choice. J. Bus. Res. 2004, 57, 873-880. [CrossRef]

37. Henderson, P.W.; Giese, J.L.; Cote, J.A. Impression Management Using Typeface Design. J. Mark. 2004, 68, 60-72. [CrossRef]

38. McCarthy, M.S.; Mothersbaugh, D.L. Effects of Typographic Factors in Advertising-Based Persuasion: A General Model and Initial Empirical Tests. Psychol. Mark. 2002, 19, 663-691. [CrossRef]

39. Hansard, T.C. Typographia; Cambridge University Press: Cambridge, UK, 2010; ISBN 9780511792762.

40. Jones, M.N.; Mewhort, D.J.K. Case-sensitive letter and bigram frequency counts from large-scale English corpora. Behav. Res. Methods Instrum. Comput. 2004, 36, 388-396. [CrossRef] [PubMed]

41. Avramides, A. Studies in the Way of Words. Philos. Books 1992, 31, 228-229.

42. Wang, T. Fonts and Fluency: The Effects of Typeface Familiarity, Appropriateness, and Personality on Reader Judgments. Masters' Thesis, University of Canterbury, Christchurch, New Zealand, 2012.

43. Sennett, R. Authority; W. W. Norton \& Company: New York, NY, USA, 1993.

44. Pham, M.T. Cue Representation and Selection Effects of Arousal on Persuasion. J. Consum. Res. 1996, 22, 373-387. [CrossRef]

45. Cialdini, R.B.; Goldstein, N.J. Social Influence: Compliance and Conformity. Annu. Rev. Psychol. 2004, 55, 591-621. [CrossRef] [PubMed]

46. Bandura, A.; Reese, L.; Adams, N.E. Microanalysis of action and fear arousal as a function of differential levels of perceived self-efficacy. J. Pers. Soc. Psychol. 1982, 43, 5-21. [CrossRef] [PubMed]

47. Mehrabian, A.; Russell, J.A. An Approach to Environmental Psychology; The MIT Press: Cambridge, MA, USA, 1974; Volume 315, ISBN 0262130904.

48. Bajaj, A.; Bond, S.D. Beyond beauty: Design symmetry and brand personality. J. Consum. Psychol. 2018, 28, 77-98. [CrossRef]

49. Pina, J.M.; Dall'Olmo Riley, F.; Lomax, W. Generalizing spillover effects of goods and service brand extensions: A meta-analysis approach. J. Bus. Res. 2013, 66, 1411-1419. [CrossRef]

50. Giles, M.; Evans, A. External Threat, Perceived Threat, and Group Identity. Soc. Sci. Q. 1985, 66, 50.

51. Holbert, R.L.; Shah, D.V.; Kwak, N. Fear, Authority, and Justice: Crime-Related TV Viewing and Endorsements of Capital Punishment and Gun Ownership. J. Mass Commun. Q. 2004, 81, 343-363. [CrossRef]

52. Feldman, S.; Stenner, K. Perceived Threat and Authoritarianism. Polit. Psychol. 1997, 18, 741-770. [CrossRef]

53. Sheldon, K.M.; Kasser, T. Coherence and congruence: Two aspects of personality integration. J. Pers. Soc. Psychol. 1995, 68, 531-543. [CrossRef] [PubMed]

54. Newman, K.L.; Nollen, S.D. Culture and Congruence: The Fit Between Management Practices and National Culture. J. Int. Bus. Stud. 1996, 27, 753-779. [CrossRef]

55. Solomon, M.R.; Ashmore, R.D.; Longo, L.C. The Beauty Match-Up Hypothesis: Congruence between Types of Beauty and Product Images in Advertising. J. Advert. 1992, 21, 23-34. [CrossRef]

56. Lee, Y.H.; Mason, C. Responses to Information Incongruency in Advertising: The Role of Expectancy, Relevancy, and Humor. J. Consum. Res. 1999, 26, 156-169. [CrossRef]

57. Moore, R.S.; Stammerjohan, C.A.; Coulter, R.A. Banner advertiser-web site context congruity and color effects on attention and attitudess. J. Advert. 2005, 34, 71-84. [CrossRef]

58. Feinberg, M.; Willer, R. The Moral Roots of Environmental Attitudes. Psychol. Sci. 2013, 24, 56-62. [CrossRef] [PubMed]

59. Tappin, B.M.; Capraro, V. Doing good vs. avoiding bad in prosocial choice: A refined test and extension of the morality preference hypothesis. J. Exp. Soc. Psychol. 2018, 79, 64-70. [CrossRef] 
60. Wolsko, C.; Ariceaga, H.; Seiden, J. Red, white, and blue enough to be green: Effects of moral framing on climate change attitudes and conservation behaviors. J. Exp. Soc. Psychol. 2016, 65, 7-19. [CrossRef]

61. Dickinson, J.L.; McLeod, P.; Bloomfield, R.; Allred, S. Which Moral Foundations Predict Willingness to Make Lifestyle Changes to Avert Climate Change in the USA? PLoS ONE 2016, 11, e0163852. [CrossRef] [PubMed]

62. Capraro, V.; Rand, D.G. Do the right thing: Experimental evidence that preferences for moral behavior, rather than equity and efficiency per se, drive human prosociality. Judgm. Decis. Mak. 2018, 13, 99-111. [CrossRef]

63. Capraro, V.; Vanzo, A. Understanding Moral Preferences Using Sentiment Analysis. SSRN Electron. J. 2018. [CrossRef]

64. Tannenbaum, M.B.; Hepler, J.; Zimmerman, R.S.; Saul, L.; Jacobs, S.; Wilson, K.; Albarracín, D. Appealing to fear: A meta-analysis of fear appeal effectiveness and theories. Psychol. Bull. 2015, 141, 1178-1204. [CrossRef] [PubMed]

65. Popova, L. The Extended Parallel Process Model. Heal. Educ. Behav. 2012, 39, 455-473. [CrossRef] [PubMed]

66. Hartmann, P.; Apaolaza, V.; D'Souza, C.; Echebarria, C.; Barrutia, J.M. Nuclear power threats, public opposition and green electricity adoption: Effects of threat belief appraisal and fear arousal. Energy Policy 2013, 62, 1366-1376. [CrossRef]

67. Witte, K. Fear control and danger control: A test of the extended parallel process model (EPPM). Commun. Monogr. 1994, 61, 113-134. [CrossRef]

68. Riley, M.W.; Hovland, C.I.; Janis, I.L.; Kelley, H.H. Communication and Persuasion: Psychological Studies of Opinion Change. Am. Sociol. Rev. 1954, 19, 355-357. [CrossRef]

69. Kligyte, V.; Connelly, S.; Thiel, C.; Devenport, L. The Influence of Anger, Fear, and Emotion Regulation on Ethical Decision Making. Hum. Perform. 2013, 26, 297-326. [CrossRef]

70. Leshner, G.; Bolls, P.; Wise, K. Motivated processing of fear appeal and disgust images in televised anti-tobacco ads. J. Media Psychol. 2011, 23, 77-89. [CrossRef]

71. Rossiter, J.R.; Thornton, J. Fear-pattern analysis supports the fear-drive model for antispeeding road-safety TV ads. Psychol. Mark. 2004, 21, 945-960. [CrossRef]

72. Laroche, M.; Toffoli, R.; Zhang, Q.; Pons, F. A cross-cultural study of the persuasive effect of fear appeal messages in cigarette advertising: China and Canada. Int. J. Advert. 2001, 20, 297-317. [CrossRef]

73. Johnston, A.C.; Warkentin, M. Warkentin Fear Appeals and Information Security Behaviors: An Empirical Study. MIS Q. 2010, 34, 549-566. [CrossRef]

74. O'Neill, S.; Nicholson-Cole, S. Fear Won't Do It: Promoting Positive Engagement With Climate Change Through Visual and Iconic Representations. Sci. Commun. 2009, 30, 355-379. [CrossRef]

75. Charry, K.M.; Demoulin, N.T.M. Behavioural evidence for the effectiveness of threat appeals in the promotion of healthy food to children. Int. J. Advert. 2012, 31, 773-794. [CrossRef]

76. Skurka, C.; Niederdeppe, J.; Romero-Canyas, R.; Acup, D. Pathways of Influence in Emotional Appeals: Benefits and Tradeoffs of Using Fear or Humor to Promote Climate Change-Related Intentions and Risk Perceptions. J. Commun. 2018, 68, 169-193. [CrossRef]

77. Ben-Zeev, T.; Fein, S.; Inzlicht, M. Arousal and stereotype threat. J. Exp. Soc. Psychol. 2005, 41, $174-181$. [CrossRef]

78. Dodson, J.D. The relation of strength of stimulus to rapidity of habit-formation in the kitten. J. Anim. Behav. 1915, 5, 330-336. [CrossRef]

79. Misra, S.; Beatty, S.E. Celebrity spokesperson and brand congruence: An assessment of recall and affect. J. Bus. Res. 1990, 21, 159-173. [CrossRef]

80. Only One Earth Day 200: Collapse of Global Civilization Inevitable?-Economist's Journey to Life. Available online: http:/ / economistjourneytolife.blogspot.com/2013/03/day-200-collapse-of-global-civilization.html (accessed on 20 December 2018).

81. The 25 Most Used Typefaces in Advertising-MDirector.com. Available online: https://www.mdirector. com/en/digital-marketing/25-typefaces-advertising.html (accessed on 18 November 2018).

82. Brañas-Garza, P.; Capraro, V.; Rascón-Ramírez, E. Gender differences in altruism on Mechanical Turk: Expectations and actual behaviour. Econ. Lett. 2018, 170, 19-23. [CrossRef]

83. Choi, S.M.; Rifon, N.J. It Is a Match: The Impact of Congruence between Celebrity Image and Consumer Ideal Self on Endorsement Effectiveness. Psychol. Mark. 2012, 29, 639-650. [CrossRef]

84. Zimmer, M.R.; Stafford, T.F.; Stafford, M.R. Green Issues: Dimension of Environmental Concern. J. Bus. Res. 1994, 30, 63-74. [CrossRef] 
85. Dunlap, R.E.; Van Liere, K.D. The "new environmental paradigm". J. Environ. Educ. 1978, 9, 10-19. [CrossRef]

86. Bolin, J.H. Introduction to Mediation, Moderation, and Conditional Process Analysis: A Regression-Based Approach. New York, NY: The Guilford Press. J. Educ. Meas. 2014, 51, 335-337. [CrossRef]

87. Bottom, W.P. Heuristics and Biases: The Psychology of Intuitive Judgment. Acad. Manag. Rev. 2004, 29, 695-698. [CrossRef]

88. Bechara, A.; Damasio, H.; Damasio, A.R. Role of the Amygdala in Decision-Making. Ann. N. Y. Acad. Sci. 2006, 985, 356-369. [CrossRef]

89. Öhman, A. The role of the amygdala in human fear: Automatic detection of threat. Psychoneuroendocrinology 2005, 30, 953-958. [CrossRef] [PubMed]

90. Adolphs, R.; Gosselin, F.; Buchanan, T.W.; Tranel, D.; Schyns, P.; Damasio, A.R. A mechanism for impaired fear recognition after amygdala damage. Nature 2005, 433, 68-72. [CrossRef] [PubMed]

91. Puntoni, S.; de Langhe, B.; van Osselaer, S.M.J. Bilingualism and the Emotional Intensity of Advertising Language. J. Consum. Res. 2009, 35, 1012-1025. [CrossRef]

92. Piller, I. Advertising as a site of language contact. Annu. Rev. Appl. Linguist. 2003, 23, 170-183. [CrossRef]

93. Cauberghe, V.; De Pelsmacker, P.; Janssens, W.; Dens, N. Fear, threat and efficacy in threat appeals: Message involvement as a key mediator to message acceptance. Accid. Anal. Prev. 2009, 41, 276-285. [CrossRef] [PubMed]

94. Johnston, A.C.; Warkentin, M.; Siponen, M. An Enhanced Fear Appeal Rhetorical Framework: Leveraging Threats to the Human Asset Through Sanctioning Rhetoric. MIS Q. 2015, 39, 113-134. [CrossRef]

95. Chung, H.; Ahn, E. The Effects of Fear Appeal: A Moderating Role of Culture and Message Type. J. Promot. Manag. 2013, 19, 452-469. [CrossRef]

(C) 2019 by the authors. Licensee MDPI, Basel, Switzerland. This article is an open access article distributed under the terms and conditions of the Creative Commons Attribution (CC BY) license (http:/ / creativecommons.org/licenses/by/4.0/). 